\section{BioLogos Deletes an Article}

\author{
S. Joshua Swamidass (D) \\ https://doi.org/10.54739/rv8k
}

A year ago, yesterday, BioLogos ${ }^{1}$ quietly deleted an article, from 2010, published on their website, " Does Genetics Point to a Single Primal Couple?" The deleted article reports, incorrectly, that any notion of Adam and Eve, ancestors of us, is in conflict with the genetic evidence.

The claims made in the 2010 article, however, went far beyond the evidence. The authors claimed conflict between science and traditional readings of Scripture where there was none.

Still, this article would come to have an outsized influence. Dennis Venema was one of the scientists who authored this article. In Adam and the Genome (2017), Venema recounts how the claims in this article were presented to a larger audience.

\begin{abstract}
Asked how likely it is that we all descended from Adam and Eve, Dennis Venema, a biologist at Trinity Western University, replies: "That would be against all the genomic evidence that we've assembled over the last 20 years, so not likely at all."
\end{abstract}

Evangelicals Question The Existence Of Adam And Eve, NPR, (2011) quoted in Adam and the Genome (2017).

Christianity Today, also, published a widely read cover story covering these claims. The 2010 article became the cornerstone of BioLogos's scientific position on Adam and Eve.

The problem, however, was that Venema's response to the reporter was just not true. To the contrary, the best evidence at the time showed that Adam and Eve, if they were real people in a real past, would most likely be ancestors of us all. If they were ancient, maybe the evidence many not even demand there were people outside the garden.

Whether Adam and Eve were recent or ancient, we all could be, "as C.S. Lewis puts it in his Chronicles of Narnia, the 'sons of Adam and daughters of Eve."” This is all "consistent with the genomic evidence we've assembled" over the last several decades.

The science here is interesting. William Lane Craig's upcoming book on Adam and Eve is addressing some of the science. He relies heavily on a dialogue between Dennis Venema and others back in 2017, which was summarized on our forum at the time. This also includes

1. BioLogos is an organization founded by Francis Collins, current director of the NIH. They advocate "evolutionary creation," a particular theology of human origins.

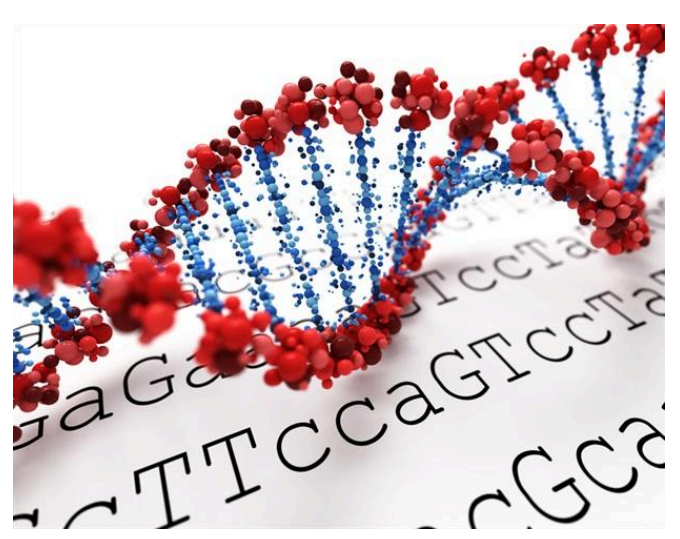

work we've done in collaboration with Reasons to Believe. The full story of how these errors came to light is for another day.

We are finding that genetics gives us unprecedented insight into the past, but it is not the whole story.

A careful account of the genetic evidence makes space for a wide range of views about human origins, from William Lane Craig, to Hugh Ross at Reasons to Believe, to ideas in The Genealogical Adam and Eve.

In this newfound space, many of us have together returned to the grand conversation of origins, wondering about what it means to be human. This is the pay off, the opportunity, that comes from getting the science straight.

\section{Please "Retract" This Article?}

The 2010 article was just not good science. It had a large impact on the conversation, and that impact should be undone.

The mistakes in this article should have been recognized at the time, back in 2010, when it was published. This was not just one mistake but several, and the scientific issues grow if we consider the subsequent efforts to defend the 2010 article's faulty conclusions. The errors extend well beyond what I addressed in my recent book on genealogical ancestry; though related, the issues uncovered in the 2010 article reflect different and larger scientific mistakes.

It is good to see BioLogos, at long last, back away from the 2010 article and its conclusions.

We should not harshly criticize BioLogos for misunderstanding the science here. Science is complex and nuanced. All of us make mistakes at one point or another. What matters now is if and how these mistakes are corrected.

Quietly deleting such an important article with scientific content, however, lacks transparency. The original link now redirects to a series of articles defending the deleted article's conclusions. This series of articles, in fact, has scientific errors of their own. Unfortunately, the only place to read the deleted article and what was wrong with it, now, is at Peaceful Science. There was no explanation on their website. ${ }^{2}$ 
The article, instead, should be "retracted," which means putting it back online with a note clarifying the scientific issues, not just deleted. As influential as it was, the article had serious scientific errors.

In science, we have specific and high standards of transparency on matters like this. When significant errors are made, how we correct them it is a matter of ethics. Scientists care to correct the official record, especially when it has misled the public. Private acknowledgement is not enough, and this is why we never delete scientific articles. Instead, we leave them online, with a note explaining what we got wrong.

So, back in January 2020, I asked BioLogos to put this article back online, with an explanation of what was wrong with it. I asked them to retract the article.

After a year of waiting, they did not do so. Private conversation this last year with BioLogos has not resolved the matter. Key biologists at BioLogos agree that the article is in error, even confirmed this with an expert in population genetics. ${ }^{3}$ They have not been willing to state this publicly.

So, let me make this request publicly then. Please put it back online with a note explaining what it got wrong?

\section{Please retract this article?}

It has been almost a decade since the article was first was published in 2010, a year since it was deleted, a couple months now since my last exchange with BioLogos. The article is still deleted, without any explanation.

Please tell us why is it taking years to correct this mistake and clear the record? Why not just put the article back online with an explanation of where it went wrong?

\section{Moving Forward With Transparency}

There is an opportunity here.

Retracting this article, also, is an opportunity to explain to a larger audience the science here. Explaining the science of ancestry

2. At times in 2020 , there has been nonspecific acknowledgement of

"overstatements" in articles on their website, but they did not address this article.

There was not an apology, and these acknowledgements have not been forwarded to their mailing list.

3. Dr. Hardin is a biologist, and was Chairman of the BioLogos board at the time. He wrote in January 2020, "Several of your points about things that need correction in some of Dennis Venema's pieces on the BioLogos web site are well-taken, and confirmed by an expert in population genetics I consulted. The issues include the improper use of "minimum" vs. "average" population size, the notion of "severity" of a bottleneck involving both size and duration (not just size), limitations of SNPbased approaches, issues related to the use of incomplete lineage sorting data, and imprecision about taxonomic categories of ancestors." pertaining to Adam and Eve is closely connected to BioLogos' mission, and it is surprising they have not already taken this opportunity.

Science demands we transparently acknowledge and correct our mistakes. Transparency is critical, because it helps bring us to shared understanding. Transparency is how new consensus is forged.

It does not seem that BioLogos is following the standards we expect of scientists, but it is not too late. Their absence from the dialogue is conspicuous, but it need not be permanent.

Speaking to larger concerns, they could agree with Nathan Lents and I, "Of course, when science conflicts with particular religious claims, we must not remain silent...however, when scientific evidence is silent on religious beliefs, we should simply admit that, rather than sow harmful conflict." Honesty serves the common good.

Many of us are returning to the grand questions of human origins. In time, hopefully evolutionary creationists will join the conversation too. We have common ground, but also disagreements. Even where we disagree, their voice is important, and it is missed.

On January 15, 2021, based on helpful reader feedback, we substantially rewrote the last half of the article, to remove some sensitive information and make more clear our request to BioLogos. We are not aware of any factual errors in the original article. This was not a scientific article, but transparency is important, so we will provide the original version of article to any reader that requests it. If requested by BioLogos, moreover, we will put the full article back online too.

Our newsletter, also, states,

Discussing this topic may not be comfortable, but Peaceful Science seeks common ground alongside clarity regarding our positions. At times, we have challenged content from other groups, such as the ID movement. This critique of BioLogos is in the same vein, and we hope our request and BioLogos' response moves the conversation forward.

The day of publication, the title of this article was changed to remove the word "Stealth," and the feature image was changed. The original feature image image was a picture of Deborah Haarsma. The article was also further updated for clarity and conciseness.

\section{References}

https://discourse.peacefulscience.org/t/_/9283

https://peacefulscience.org/books/adam-genome/ https://www.npr.org/2011/08/09/138957812/evangelicals-questionthe-existence-of-adam-and-eve

https://peacefulscience.org/articles/reviewing-adam-and-the-genome/ 
https://www.christianitytoday.com/ct/2011/june/historicaladam.html https://peacefulscience.org/articles/wlc-genetic-challenge/ https://discourse.peacefulscience.org/t/_/61

https://peacefulscience.org/articles/human-origins-rtb-workshop/ https://peacefulscience.org/articles/three-stories-on-adam/ https://peacefulscience.org/books/genealogical-adam-eve/ https://publicationethics.org

https://discourse.peacefulscience.org/t/_/12896 